City University of New York (CUNY)

CUNY Academic Works

\title{
CCTV as a Tool for Early Police Intervention: Preliminary Lessons from Nine Case Studies.
}

\author{
Eric Piza \\ John Jay College of Criminal Justice - City University of New York \\ Joel M. Caplan \\ School of Criminal Justice, Rutgers University \\ Leslie W. Kennedy \\ School of Criminal Justice, Rutgers University
}

\section{How does access to this work benefit you? Let us know!}

More information about this work at: https://academicworks.cuny.edu/jj_pubs/167

Discover additional works at: https://academicworks.cuny.edu

This work is made publicly available by the City University of New York (CUNY).

Contact: AcademicWorks@cuny.edu 


\title{
Original Article
}

\section{CCTV as a tool for early police intervention: Preliminary lessons from nine case studies}

\author{
Eric L. Piza ${ }^{\mathrm{a}, *}$, Joel M. Caplan ${ }^{\mathrm{b}}$ and Leslie W. Kennedy ${ }^{\mathrm{b}}$ \\ ${ }^{a}$ Department of Law and Police Science, John Jay College of Criminal Justice, 524 West 59th Street, Haaran Hall, \\ Room 422.14T, New York, NY 10019, USA. \\ E-mail: epiza@jjay.cuny.edu \\ ${ }^{\mathrm{b}}$ School of Criminal Justice, Rutgers University, 123 Washington St., Newark, NJ 07102, USA. \\ *Corresponding author.
}

\begin{abstract}
This study explores the prospect of utilizing CCTV as an early intervention mechanism to detect and disrupt street-level activity that can lead to violence. The analysis focuses on nine case studies in Newark, NJ, incorporating data from several sources, including video footage, computer-aided dispatch (CAD) system incident data, CAD event chronologies and face-to-face interviews with CCTV operators. The findings suggest that the benefits offered by CCTV, namely the instantaneous discovery and reporting of crime, may be rendered inconsequential by the process times associated with the differential-response policy of police dispatch. Potential methods by which police can more proactively utilize CCTV to prevent crime are discussed.

Security Journal (2017) 30, 247-265. doi:10.1057/sj.2014.17; published online 14 April 2014
\end{abstract}

Keywords: CCTV; police response; crime escalation; crime precursors; Newark, NJ

\section{Introduction}

CCTV has emerged as a mainstream crime prevention tool in contemporary policing. Whereas CCTV was once limited to retail stores and office buildings, surveillance cameras are now common fixtures in public spaces around the world. The tactic's rise can be traced to Great Britain, where the Home Office's 'CCTV Challenge' provided direct funding for CCTV projects between 1994 and 1997 (Painter and Tilley, 1999, p. 2). Continued government support and public enthusiasm for the tactic led to continued expansion in the following years to the extent that CCTV is widely considered Britain's 'crime prevention initiative of the century' (Norris and Armstrong, 1999a). The use of CCTV as a crime prevention tool appears to be gaining similar stature in the United States. Numerous major American cities have invested in large CCTV systems, including Baltimore (La Vigne et al, 2011), Chicago (La Vigne et al, 2011), Cincinnati (Mazerolle et al, 2002), Los Angeles (Cameron et al, 2008), Newark (Caplan et al, 2011), New Orleans (Usher, 2003), Philadelphia (Ratcliffe et al, 2009), Washington DC (La Vigne et al, 2011) and San Francisco (King et al, 2008), to name a few. 
The evaluation research on CCTV suggests that the technology can have an effect on crime in certain contexts. The meta-analysis of Welsh and Farrington (2009) found that CCTV caused a 16 per cent reduction in crime across the 44 studies included in the analysis. However, this reduction was largely driven by the car park systems, which produced a 51 per cent decrease in crime with most other settings experiencing small, statistically insignificant crime reductions. Later evaluations produced findings that can be best classified as 'mixed', with CCTV reducing crime in certain situations and having little effect in others (Mazerolle et al, 2002; Ratcliffe et al, 2009; Caplan et al, 2011; La Vigne et al, 2011; Piza et al, 2013; Reid and Andresen, 2014). This body of research has greatly contributed to our understanding of CCTV's deterrence effects. What is not as well understood is the precise manner by which CCTV can prevent crime. In particular, little attention has been paid to CCTV's logistical role in policing, the benefits it provides law enforcement, and whether police are able to effectively make use of said benefits.

This study expands upon previous research by examining an alternate use of publically deployed video surveillance cameras. Specifically, this study explores the potential use of CCTV as an early intervention mechanism in the prevention of serious street violence. Through the coding of video footage, official police records and interviews with surveillance operators, we explore how the proactive use of CCTV may provide police with legal grounds to intervene in situations preceding serious acts of violence. We further explore whether standard police deployment practices realize the opportunities from such opportunities. We conclude with a discussion of how the proactive identification of intervention opportunities via surveillance cameras may be effectively incorporated into the police mission.

\section{Review of Relevant Literature}

In discussing the crime prevention utility of CCTV, Ratcliffe (2006) articulated, 'a CCTV system is not a physical barrier. It does not limit access to certain areas, make an object harder to steal, or a person more difficult to assault and rob ... It seeks to change offender perception so the offender believes if he commits a crime, he will be caught' (p. 8). The focus on offender perception aligns CCTV with the Rational Choice theory (Cornish and Clarke, 1986), which emphasizes offender decision-making in explaining crime commission. Essentially, offenders consider the risk and rewards of a given criminal opportunity and refrain from offending only when the costs outweigh the benefits (Clarke, 1997). This riskcalculus involves a number of 'choice structuring properties', which include the pros, cons and inherent risk involved in the commission of a particular crime. The decision to offend is 'the outcome of an appraisal process which...evaluates the relative merits of a range of potential courses of action, comprising all those thought likely in the offender's view to achieve his or her current objective (for example, for money, sex, or excitement)' (Cornish and Clarke, 1987, p. 935). In regards to CCTV, this 'appraisal process' must result in the potential offender determining that camera presence carries an increased level of risk for deterrence to be achieved.

The deterrent capabilities of CCTV has predominately been tested through pre/post measurements of crime in camera areas (Mazerolle et al, 2002; Gill and Spriggs, 2005; Farrington et al, 2007; Ratcliffe et al, 2009; Caplan et al, 2011; La Vigne et al, 2011). Although CCTV's effect on crime counts is obviously a worthwhile research endeavor, the 
emphasis on outcomes has led to the under-exploration of the contextual mechanisms by which deterrence can be achieved. For example, Pawson and Tilley (1994) offered eight mechanisms by which CCTV can prevent crime $^{1}$ while others have noted the importance of swift police response and apprehension of offenders detected by CCTV (Tilley, 1993; Piza et al, 2012). The exclusive emphasis on outcomes precludes the understanding of how such procedural aspects of CCTV may influence deterrence.

Although the CCTV literature continues to be predominately outcome-based, a body of knowledge has surfaced focusing on procedural aspects of the technology. This research has typically focused on two issues: (1) the number of incidents detected by CCTV and (2) the manner by which operators select targets for surveillance. This research has identified some general findings. For one, despite the emphasis many operations place on the live monitoring of cameras, operator activity is often low. This finding is consistent across various operational definitions of activity, such as crimes reported to police by CCTV operators (Piza et al, 2012), arrests in response to CCTV detections (Ditton and Short, 1999; Norris and Armstrong, 1999b; Piza et al, 2012), evidence or intelligence captured by CCTV (Sarno et al, 1999; Waples and Gill, 2006; King et al, 2008), and proactive 'targeted surveillances' conducted by CCTV operators (Norris and Armstrong, 1999a; Lomell, 2004; Norris and McCahill, 2006). Researchers have provided a variety of explanations for the consistently low-levels of activity, including the often high camera to operator ratio (Keval and Sasse, 2010; Piza et al, 2012), the lack of formal training of operators (Bulos and Sarno, 1996; Loveday and Gill, 2004), lack of motivation on the part of operators (Norris and McCahill, 2006), and the fact that operators are often tasked with responsibilities unrelated to the proactive monitoring of cameras (Leman-Langlois, 2002; Gill et al, 2005). Regarding target selection, studies commonly find physical appearance, rather than behavior, to be a common factor leading operators to focus upon specific individuals or groups. Certain studies have suggested that race and ethnicity provoke operator attention (Norris and Armstrong, 1999a, b) while others have found that styles of dress and unkempt appearances lead to higher levels of surveillance, especially in the case of young males (Lomell, 2004; Loveday and Gill, 2004; Smith, 2004). Such findings offer a certain level of support to antisurveillance positions (see ACLU, 2002; Lyon, 2003) and point to the importance of training and supervision in the surveillance function.

Although observational studies provide important insight into operator decision making and behavior, little is known on the precise manner by which the live monitoring of cameras is integrated into the police function. A noteworthy exception is Gill and Spriggs (2005), who conducted an in-depth process evaluation in conjunction with an impact evaluation of 13 CCTV systems in Great Britain. The process evaluation focused on control room design and management as well as communication between CCTV operators and police officers. Their findings suggest that these procedural aspects are related to the overall efficiency and effectiveness of the CCTV operations. Unfortunately, research has typically considered the operator function separate from the crime prevention utility of CCTV, despite the fact that operator actions may impact crime in a number of ways. For one, whether or not infractions occurring within sight of cameras are discovered is largely dependent on CCTV operators. CCTV operators can also guide responding officers to the specific incident at hand and can provide detailed information on the involved parties.

There is also the under-researched benefit of CCTV identifying incidents in their early stages, which can facilitate early intervention and prevent escalation to a more serious crime 
(Owen et al, 2006). In their discussion of risk and crime, Kennedy and Van Brunschot (2009) discuss the potential for police to utilize CCTV to address underlying risk factors. The authors build upon the framework of Sacco and Kennedy (2002), who explain crime from a risk perspective in which events unfold in three stages, precursor, transaction and aftermath. The standard use of CCTV predominately relies on the passive presence of cameras to generate deterrence, which arguably does little to address risk factors present in the precursor stage. Street-violence provides a telling example. Many violent crimes result from precursor events, such as the escalation of relatively minor disputes (Jacobs et al, 2000; Ratcliffe and Rengert, 2008). In this sense, CCTV can detect a quarrel before it turns into an assault or an open-air drug transaction before it generates a robbery. Detection of precursor events by CCTV operators may provide a means for police to prevent serious offending. In fact, Gill and Hemming (2004) found that 25 per cent of street fights in Lewisham occurring over the study period were first detected and reported to police by CCTV operators, showing how surveillance can offer police a 'head start' in addressing incidents before they escalate to a point of serious injury. As argued by Kennedy and Van Brunschot (2009), the '[a]ctive rather than passive use of this technology in managing public areas may afford an important new resource in the reduction of risk' (p. 141).

Recent research may provide a level of support (albeit indirectly) for the use of CCTV as an early intervention tool. In their study of CCTV in three US cities (Baltimore, Chicago and Washington DC), La Vigne et al (2011) found the systems that effectively reduced crime were those that were actively monitored and heavily incorporated into the police function. Conversely, the systems removed from proactive police activities produced no tangible crime control benefits. Piza et al (2013) found evidence of a similar intra-system mechanism, with CCTV-generated enforcement actions being related to decreases in overall crime, violent crime, and theft from auto within individual camera viewsheds in Newark, NJ. This finding suggests that the individual camera sites most utilized in the proactive activities of the surveillance unit experienced the largest crime control benefits, with those detached from proactive enforcement not generating crime reductions. The findings of these studies have mostly been attributed to the increased certainty of punishment within CCTV areas, which research has demonstrated to be of the utmost importance in generating deterrence (Durlauf and Nagin, 2011; Apel, 2013). However, both La Vigne et al (2011) and Piza et al (2013) gave little detail on the nature of the police enforcement activities relative to the CCTV operations, meaning that the disruption of precursor risk factors may have also contributed to the crime reductions.

\section{Scope of the Current Study}

This study explores the prospect of utilizing CCTV as an early intervention mechanism, specifically through the exploration of nine case studies. We define case study in the traditional sense of social-science research methodology, a multi-faceted investigation of a relatively small number of cases, relying on the use of several data sources (Feagin et al, 1991; Hammersley, 1992). We acknowledge the often-cited limitations of the case study method, specifically that the low $N$ prevents the findings from being generalized (Platt, 2007). However, we also recognize the case study method as an avenue for the exploration of unique patterns within cases for the purpose of better understanding the nature and scope of a 
social phenomenon of interest (Platt, 2007). Others have argued that the development of evidence-based practice is contingent upon the use of diverse methodologies that can generate useful information for practitioners (Lum and Kennedy, 2012). These observations have particular salience in policing, where the 'ordinary process of discovery' can provide insight into key aspects of crime problems even in the absence of statistically robust research designs (Sparrow, 2011).

We analyzed video footage immediately preceding the commission of a violent crime at the same location in Newark, NJ and explored how CCTV operator actions may offer police opportunities for early intervention in such incidents. We compared the time frames between the early intervention opportunities and the commission of a violent crime to median officer response times to gauge whether a police response to the precursor event could have potentially prevented the ensuing violence. We also interviewed the operators who detected the incidents to gain a sense of their decision-making relative to the observation and reporting (or lack thereof) of the infractions preceding the violent crime incident. Collectively, the data provide a basis on which to explore CCTV's capacity to facilitate interventions.

\section{Research Setting}

This study focuses on the police-monitored CCTV system in Newark, NJ, which comprises 146 cameras. All of the cameras are PTZ units whose 'pan', 'tilt' and 'zoom' functions are directly controlled by the user. The Video Surveillance Unit (VSU) of the Newark Police Department monitors the video feeds of each camera. Over the study period, VSU was staffed by two civilian video operators under the supervision of a police sergeant. The video operators were tasked with monitoring the cameras for the purpose of detecting incidents of crime and disorder. Upon detecting such an incident, operators report the event via the department's computer-aided dispatch (CAD) system. Reported incidents (both CCTV events and 9-1-1 calls for service) are stored in CAD's calls-pending-queue. These assignments are addressed in a differential response manner by the police dispatcher, with higher priority incidents taking precedence over those with lower priority levels. This process is considered standard operating procedure in police departments across the United States (LEITSC, 2008). The video surveillance system also has the capability to store and save footage. By default, all camera feeds are stored on the system for a 30-day period, at which time the footage is overwritten. However, portions of footage can be exported and stored indefinitely onto hard drives or removable discs. In Newark, footage of crime incidents has been exported and later used for investigative purposes by NPD detectives and as evidence by municipal, county and federal prosecutors.

\section{Data Sources and Methods}

This study utilizes data from three separate sources, video footage immediately preceding and including a violent crime, the Newark Police Department's CAD system, and face-toface interviews with surveillance operators who conducted the surveillances. Each data source underwent specific procedures of data collection and analysis, which are described below. 


\section{Incident footage}

Footage used in this study was identified through VSU's Video Control Ledger, which lists all incidents burned on DVD for investigative and evidentiary purposes. Researchers had access to records for incidents occurring from October 2007 through December 2009. In total, 332 discs were labeled as pertaining to a Part 1 violent crime incident. ${ }^{2}$ However, the vast majority of these were unusable for the purpose of the study. Although each disc referenced a particular incident (for example, 'Robbery, 10/1/07, 100 Main St') most footage covered a different time/area than that of the actual incident. This was done at the request of detectives for investigative purposes. For example, while a crime may have happened on 10/ 1/07 at 100 Main St, a detective may request footage from a camera in another area or from another date to see if anything of evidentiary value (for example, a felony vehicle fleeing the scene, suspects returning to the crime scene, and so on) was captured on video. In total, only 13 discs were of a Part 1 violent crime incident actually detected by the CCTV cameras, despite the fact that VSU records show that the unit detected 73 Part 1 violent crimes over the study period. When asked about this discrepancy, the commanding officer of VSU stated that the unit only saves footage at the request of police officers or detectives, which primarily occurs when the CCTV system provides the sole source of probable cause for an arrest. For example, if a police officer does not apprehend the suspect in question, the footage of the crime incident is not saved. In addition, while VSU may have detected a robbery in progress, a responding officer may have been told by the victim that a robbery occurred, granting him/ her grounds for arrest based on their personal knowledge of the event. In such an instance, CCTV footage would not be saved since it was not the sole source of probable cause. In the case of detectives, the VSU commander stated that they often responded to VSU following a crime in order to view the footage first hand. If the footage did not add anything of evidential value to their investigation, they normally did not request a copy.

An additional four incidents were unusable for this study due to insufficient time lengths of the video. In these cases, CCTV operators captured only the crime in question without any preceding surveillance taking place. This left nine violent crime incidents for use in this study, three shootings (two fatal and one non-fatal), one shots-fired incident (where victims were shot at but not struck by gunfire), two robberies (one gun and one 'strong arm'), and three assaults (two beatings and one stabbing).

After identifying the necessary footage, researchers viewed and coded each incident, attempting to identify specific events that provided police with legal grounds to intervene before the occurrence of the violent crime. Such events were termed 'intervention opportunities' and classified into two categories, those providing probable cause for police enforcement (such as an arrest) and those providing reasonable suspicion for a police response (to investigate whether further enforcement action is warranted). As per the Fourth Amendment of the United States Constitution, probable cause is necessary for the search and seizure of individuals suspected of a crime. Although the Fourth Amendment does not explicitly define probable cause, it is considered as a law enforcement agent's reasonable belief that the law was violated based on facts that 'are such that a reasonably discreet and prudent man would be led to believe that there was a commission of the offense charged' (Dumbra v. United States, 1925). Events providing probable cause in this study ranged from a street fight between two large groups to a woman throwing trash cans and undressing in the middle of a busy thoroughfare. Reasonable suspicion refers to events that on their own 
don't warrant formal sanction, but offer police 'supported articulable facts that a criminal offense has been or is about to be committed' (Terry v. Ohio, 1968), thereby granting officers legal grounds to intervene. To use an example from this project, a motorist pulled over at a corner where a group of males stood. One of the males walked to the car, leaned over seemingly to speak to the front seat passenger, reached into his back pocket, and then 'shook hands' with the passenger after which the vehicle immediately drove off. Although this act in itself is not illegal, the behavior is indicative of a hand-to-hand drug transaction and provides legal grounds for police to stop and question the persons involved. After noting all of the intervention opportunities, researchers watched the footage with the video operator who captured the incident and asked him or her to confirm or invalidate each intervention opportunity and identify any incidents the researchers failed to notice.

For each intervention opportunity, the researchers recorded the time of the event and calculated the number of minutes before the violent crime occurred. The total number of minutes between the intervention opportunity and the violent crime incident constituted the 'minutes to incident' (MTI) variable, which quantified how long police had to intervene before the crime occurred. For example, if a drug transaction occurring at 21:00 is observed on video, and a shooting occurs at this same location at 21:10, the MTI is $10 \mathrm{~min}$.

\section{Computer-aided dispatch (CAD) system}

The CAD system is used to support police dispatch and response functions while storing key data on all events brought to the attention of the police. In addition to incident data, such as event number and final disposition, CAD also contains narrative data denoting all communications between the complainant, police dispatcher and responding officers (Boba, 2009, p. 92). The Newark Police Department's CAD system was utilized for two distinct purposes. Firstly, we measured if the MTI offered by each intervention opportunity provided a realistic time frame for police to arrive before the occurrence of the violent crime. In fulfillment of this task, we incorporated data on Newark police officer response times utilized by Piza et al (2012), who analyzed all CCTV detections and 9-1-1 calls occurring in CCTV areas of Newark from 2007 through 2010 to test whether enforcement rates differed across these two reporting methods. We specifically utilized three temporal variables compiled by Piza et al (2012): queue time (the number of minutes between the reporting of the event and police dispatch); response time (the number of minutes between police dispatch and officer arrival on scene) and process time (the numeric sum of the queue time and response time variables). ${ }^{3}$ In order to tailor the data to the current study, we only included the $10799^{4}$ incidents occurring between 2007 and 2009 in the analysis.

To determine the feasibility of officers arriving on scene before the occurrence of the violent crime incident, each intervention opportunity had its corresponding MTI compared with the median process time associated with incidents sharing its same priority level. For example, in the hypothetical situation outlined previously, the unverified drug transaction had a priority level of four, as determined by the Newark Police Department's assignment codes. If the median response time for priority four incidents was $8 \mathrm{~min}$, we would conclude that police would have likely arrived before the crime occurrence, due to the transaction occurring $10 \mathrm{~min}$ before the shooting. 
Event chronologies for each violent crime incident were the second data source extracted from CAD. Event chronologies contain narrative data on pertinent factors relayed by the involved parties. Each comment is time stamped within CAD (in 'hh:mm:ss' format), providing a precise time for its occurrence. We were specifically interested in the actions taken by CCTV operators preceding the violent crime incident and noted such on each event chronology. We noted additional comments made by operators that conveyed information pertinent to the police response and/or follow-up investigation, such as suspect description and direction of flight. Similar information obtained from 9-1-1 calls were also recorded to provide a comparison for the CCTV data.

\section{Operator interviews}

The primary author of this article conducted face-to-face interviews with each operator who detected an incident included in this study. In total, interviews lasting between 30 and 45 min were conducted with seven of the nine operators assigned to the VSU during the study period. The interviews had a fairly unstructured manner, although similar questions were asked in each interview. In addition to being asked to validate or dismiss each intervention opportunity identified by the researchers, operators were asked to discuss their decision-making relative to the monitoring of specific persons and locations as well as the reporting or overlooking of observed infractions. Additional questions related to unique portions of the footage, or were follow-up questions to operator comments.

\section{Findings}

\section{The identification of intervention opportunities}

Researchers identified 16 intervention opportunities preceding a violent crime incident, with 12 providing probable cause and four reasonable suspicion. CCTV operators agreed with all but one of the probable cause incidents. In the disputed incident, researchers saw a man holding a stick on a street corner and classified this as possession of a weapon. The operator disagreed with this classification, stating: 'He's just carrying it (the stick). He's not doing anything wrong or acting in a suspicious manner ... you really don't know what he's doing with it. You just don't have enough evidence at this point to say this is something criminal'. An operator noted an additional probable cause incident, an animated dispute between bouncers and a patron ejected from a bar, which was not detected by the researchers. This incident was added to the list of intervention opportunities.

In respect to reasonable suspicion, an incident identified as a potential hand-to-hand drug transaction was dismissed by the operator who captured the footage. The research notes describe the behavior considered suspicious by the researcher: 'The man who was previously standing alone on the corner walks back into the frame. He is walking and talking with a man who is wearing a hooded gray sweatshirt. When they reach the corner, the two men shake hands. After the hand shake, the man in the hooded sweatshirt seems to put something in his pocket. The man wearing the long black coat then enters the passenger side of a minivan, which immediately drives away'. The researcher interpreted this incident as a drug 
transaction due to 'hand shakes' commonly being used to exchange money and/or drugs between dealers and customers, and because one male seemed to place something in his pocket immediately afterwards. When asked why he did not agree with the researcher's assessment, the operator stated 'Those guys looked like they knew each other, like they were a part of the same gang. The customers are different from the dealers ... they don't associate outside of the transaction. And transactions are quick. They don't usually hang out talking to the individuals they're purchasing from'. In another incident, the operator noted two possible drug transactions not identified by the researcher. In one case, a male was frequently seen walking behind a building with other persons in the courtyard of a public housing complex. After one such occurrence, the male is seen walking from behind the building back into the courtyard while another man quickly walks towards the exit of the complex. The operator pointed out that the person exiting was walking very briskly and looking around as if to make sure no one was watching him. The operator interpreted this as a drug transaction, with the dealer (from the courtyard) and the customer (the person exiting the complex) meeting behind the building to escape the view of passer-bys and, possibly, the surveillance camera. Several minutes later, this suspected dealer took an unidentified object out of his pants pocket and passed it to a person on a bicycle who then rode towards three people who seemed to be waiting for him on the other side of the complex. The operator also interpreted this as a drug transaction, with the male on the bicycle serving as a runner making the transaction on behalf of the dealer.

After adjusting for operator observations, this study included 17 unique opportunities for police intervention: 12 incidents of probable cause and five incidents of reasonable suspicion. As displayed in Table 1, all but one of the violent crimes was preceded by at least one intervention opportunity with five having multiple. ${ }^{5}$ Intervention opportunities occurred an average of 7.04 min before the violent crime. ${ }^{6}$

Although these aggregate statistics illustrate that intervention opportunities preceded most of the crime incidents, they don't measure the prevention utility of each observation. Thus, each intervention opportunity's MTI was compared with the median process time variable

Table 1: Intervention opportunities per each violent crime incident

\begin{tabular}{llcccc}
\hline Incident & Crime type & Incidents of RS $^{\mathrm{a}}$ & Incidents of PC $^{\mathrm{b}}$ & Total IO $^{\mathrm{c}}$ & ${\text { Average } \text { MTI }^{\mathrm{d}}}^{\mathrm{a}}$ \\
\hline A & Shooting & 1 & 0 & 1 & 4.51 \\
B & Shooting & 1 & 3 & 4 & 15.78 \\
C & Shots fired & 0 & 3 & 3 & NA \\
D & Shooting & 2 & 0 & 2 & 1.07 \\
E & Gun robbery & 1 & 0 & 1 & 0.23 \\
F & Assault (beating) & 0 & 0 & 0 & 0 \\
G & Strong arm robbery & 0 & 1 & 1 & 11.13 \\
H & Assault (stabbing) & 0 & 3 & 3 & 2.13 \\
I & Assault (beating) & 0 & 2 & 2 & 5.39 \\
Total (Avg.) & & $5(0.56)$ & $12(1.33)$ & $17(1.89)$ & $(7.04)$ \\
\hline
\end{tabular}

\footnotetext{
${ }^{a}$ Reasonable suspicion.

${ }^{\mathrm{b}}$ Probable cause.

${ }^{\mathrm{c}}$ Intervention opportunities.

${ }^{\mathrm{d}}$ Minutes to incident.
} 
described in the methods section. It was decided that the median was a more valid comparison for the MTI than the average since it is less susceptible to the influence of outliers. If the MTI was smaller than the median process time, we concluded that a police officer responding to the particular intervention opportunity would have likely arrived on the scene prior to the occurrence of the violent crime incident.

As displayed in Table 2, only two of the 17 intervention opportunities exhibited an MTI less than the median process time for their respective priority levels. Both of these intervention opportunities occurred in the same crime incident. Therefore, in eight of the nine incidents intervention opportunities did not surface early enough for a police unit to be reasonably expected to arrive before the commission of the crime. These findings suggest that CCTV may be ill-suited as an early intervention mechanism. However, further review of the data suggests that the differential response method of police dispatch may be to blame for the process times being larger than the MTI values. Specifically, the amount of time incidents spend in the callspending-queue may negate the potential benefits offered by CCTV. All of the intervention opportunities had priority levels between three and five, which have substantial queue times (see Table 3). Priority five's average queue time of $9.43 \mathrm{~min}$ is more than twice the average of the overall incidents. Furthermore, priority four $(21.90 \mathrm{~min})$ and priority three $(20.85 \mathrm{~min})$ incidents have queue times more than four times the overall average. The queue time accounts for the majority of the process time, rendering the response time inconsequential. This becomes even more evident when comparing the MTI with the response time instead of the process time. Seven intervention opportunities across four violent crimes had MTI's smaller than the median response time. These findings suggest that the minimizing of the queue time could have potentially led to four times as many incidents where an officer could have realistically been expected to arrive before the violent crime occurred.

\section{The lack of formal reporting of identified intervention opportunities}

Despite the fact that eight of the nine crimes were preceded by incidents warranting police action, CCTV operators formally reported early intervention opportunities in only three cases. Prior to a fatal shooting, the operator reported a person acting in a disorderly manner and a later-occurring fist fight involving this same individual. In two other incidents, an operator reported an argument between bouncers and a person ejected from a bar, and an argument between two large groups outside of a housing complex. For all other incidents, official operator action is not recorded in CAD until after the commission of the violent crime. $^{7}$

The absence of an operator action in three of the incidents is easily explained. In one, multiple drug transactions occur only 14 seconds before a gun robbery, giving the operator little time to alert the police. In the case of a disorderly woman, operators were closely observing her running in and out of traffic, nearly being struck by automobiles several times, and (understandably) did not notice what appeared to be a drug transaction occurring across the street. Finally, a heated argument between ejected night club patrons and a bouncer was already reported via 9-1-1 by someone on the scene; there was no reason for the CCTV operator to report the incident a second time.

In respect to the eight remaining intervention opportunities (which spanned five separate incidents) the infractions occurred well before the more serious crime took precedence. 


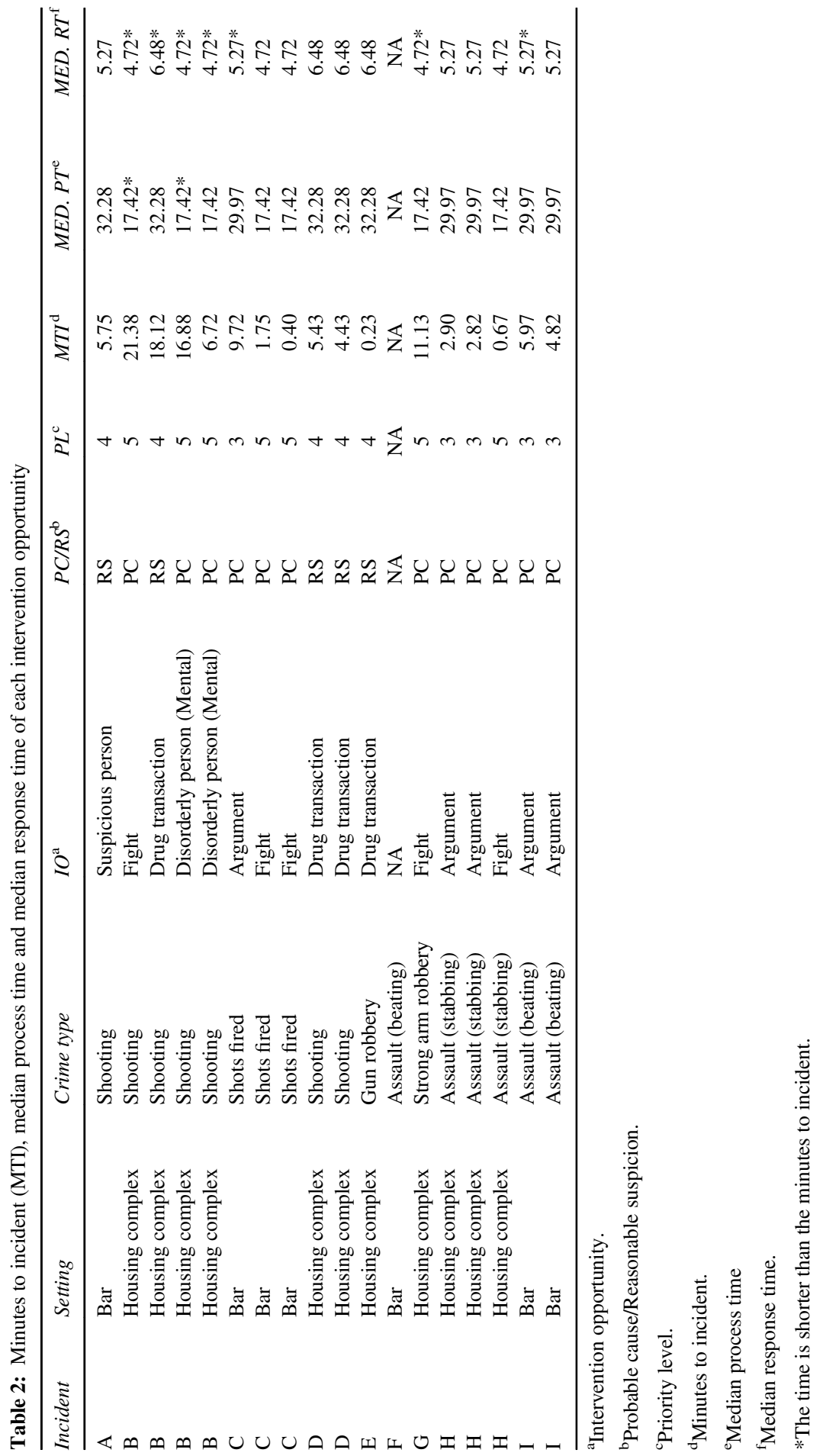


Table 3: Queue, response and process times of incidents occurring in CCTV areas

\begin{tabular}{|c|c|c|c|c|c|c|c|c|c|c|}
\hline \multirow[t]{2}{*}{$P L^{\mathrm{a}}$} & \multirow[t]{2}{*}{ FREQ. } & \multicolumn{3}{|c|}{ Qиеие time } & \multicolumn{3}{|c|}{ Response time } & \multicolumn{3}{|c|}{ Process time } \\
\hline & & $A V G$ & $S D$ & $M E D$. & $A V G$ & $S D$ & $M E D$. & $A V G$ & $S D$ & $M E D$. \\
\hline 1 & 14 & 1.70 & 4.96 & 0.00 & 1.88 & 4.55 & 0.02 & 3.58 & 8.91 & 0.02 \\
\hline 2 & 268 & 42.62 & 76.09 & 10.72 & 7.69 & 11.19 & 5.02 & 50.31 & 77.14 & 22.49 \\
\hline 3 & 1327 & 51.75 & 77.77 & 20.85 & 8.00 & 12.69 & 5.30 & $59 . .75$ & 78.86 & 29.97 \\
\hline 4 & 2341 & 45.93 & 66.45 & 21.90 & 9.12 & 11.69 & 6.40 & 55.05 & 67.26 & 32.28 \\
\hline 5 & 3181 & 28.82 & 51.09 & 9.43 & 6.70 & 8.80 & 4.67 & 35.52 & 52.41 & 17.42 \\
\hline 6 & 2079 & 4.87 & 12.60 & 1.73 & 6.50 & 9.93 & 4.12 & 11.37 & 16.63 & 6.62 \\
\hline 7 & 1568 & 2.17 & 6.68 & 0.97 & 5.42 & 8.28 & 3.68 & 7.59 & 10.64 & 5.12 \\
\hline 8 & 21 & 0.68 & 0.56 & 0.60 & 6.09 & 12.53 & 1.95 & 6.77 & 12.55 & 2.30 \\
\hline
\end{tabular}

${ }^{a}$ Priority level.

For each of these unreported intervention opportunities, operators were asked why they did not report the observed activity, particularly since they agreed with the researchers' assessment of their illegality. Operators overwhelmingly reported that aspects of police dispatch - specifically large queue times - discouraged them from reporting many of the intervention opportunities. In respect to the incident where suspected drug dealers and customers met behind a building to seemingly conduct a drug transaction, the operator said, 'since we couldn't see it directly, if we did put it into CAD it would be a low priority because we'd have to put it in as unverified (narcotics activity). So I waited to see if I could see something more concrete'. In a separate interview, when discussing his reasoning for reporting an intervention opportunity, this same operator stated 'if the queue is low, and you see something on camera, you might as well (report the incident)'. In another incident, the operator observed a group of individuals rolling and subsequently smoking what appeared to be a marijuana-filled cigar. After stating that she often views these same individuals engaging in similar behavior, the operator was asked why she didn't report the incident, to which she responded, 'Because by the time the radio car gets there they'll be long gone'. In total, four of the seven operators directly referenced queue times when explaining their reasoning for not reporting an intervention opportunity.

Operator beliefs regarding the negative influence of queue times on police response are supported by an example from this study. The previously discussed disorderly behavior of a woman was reported by an operator at 21:45. At the time of a subsequent shooting, which occurred over $21 \mathrm{~min}$ later at the same location, an officer had yet to be dispatched in response to the disorderly person offense. As reported by the operator, a string of higher priority incidents prevented police from responding to this intervention opportunity: "[On the night in question] we already had a shooting prior [to the incident in question]. All the units in this precinct were tied up either [responding to] that job or others [incidents with higher priority codes]. That's why it sat for 22 minutes... we had a lot of higher priority jobs going on'.

Although a lack of official operator involvement before crimes was evident, CCTV played an important role following the commission of each incident. Following each violent crime, CCTV operators provided pertinent information about the event, such as detailed descriptions of suspects, specific direction of flight and precise locations of weapons used in commission of the crime. For example, in one incident, a shootout occurred between two 
Table 4: The reporting of intervention opportunities and comments pertaining to the violent crime by CCTV operators and 9-1-1 callers

\begin{tabular}{|c|c|c|c|c|c|c|}
\hline \multirow[t]{2}{*}{ Incident } & \multicolumn{2}{|c|}{$\begin{array}{c}\text { Reported intervention } \\
\text { opportunities }\end{array}$} & \multicolumn{2}{|c|}{$\begin{array}{l}\text { Comments made } \\
\text { before crime }\end{array}$} & \multicolumn{2}{|c|}{$\begin{array}{l}\text { Comments made } \\
\text { after crime }\end{array}$} \\
\hline & $C C T V$ & $9-1-1$ & CCTV & $9-1-1$ & $C C T V$ & $9-1-1$ \\
\hline A & 0 & 0 & 0 & 0 & 3 & 0 \\
\hline B & 4 & 0 & 2 & 0 & 5 & 2 \\
\hline $\mathrm{C}$ & 0 & 0 & 0 & 0 & 4 & 0 \\
\hline $\mathrm{D}$ & 0 & 1 & $2^{\mathrm{a}}$ & 0 & 2 & 0 \\
\hline $\mathrm{E}$ & 0 & 0 & 0 & 0 & 4 & 0 \\
\hline $\mathrm{F}$ & 0 & 0 & 0 & 0 & 3 & 0 \\
\hline G & 1 & 0 & 2 & 0 & 1 & 0 \\
\hline $\mathrm{H}$ & 1 & 0 & 1 & 0 & 1 & 0 \\
\hline I & 0 & 0 & 0 & 0 & 1 & 0 \\
\hline Average & 0.67 & 0.11 & 0.63 & 0.00 & 2.67 & 0.22 \\
\hline
\end{tabular}

a Although the intervention opportunity in this incident was reported via 9-1-1, the CCTV operator provided a detailed description of the suspects and their vehicles.

disputing individuals, with only one being injured. After being shot in the leg, the victim, who actually fired his weapon first, threw his gun into an open apartment door before crawling into the same apartment. The CCTV operator alerted the dispatcher to the victim's true role in the incident, leading to his on-scene arrest and recovery of the firearm. In the two additional incidents, camera operators were credited with providing suspect and vehicle descriptions in addition to the precise direction of flight, which led to the apprehension of fleeing offenders. Apprehension would have been unlikely without this information, due to the responding officers being dispatched to the location where the incident occurred rather than the suspects' escape routes. In comparison, 9-1-1 calls provided similar information in only a single instance, where a caller provided a physical description of a suspect. In all other instances, 9-1-1 callers merely reported that an incident took place (for example, 'Someone's been shot') without providing anything of value to the immediate police response or followup investigation (Table 4).

\section{Discussion of Results}

Identified intervention opportunities in this study illustrate how CCTV may be used to prevent street violence. Twelve of the intervention opportunities were crimes in themselves, granting police probable cause to intervene. Five were incidents granting sufficient reasonable suspicion for police to respond. Although a police response would not have guaranteed the prevention of the violent crime (the perpetrator could have attacked at a different location or after the police left), we find it reasonable that the incident would have been less likely to occur had the police been present. Seven of the nine incidents had at least one intervention opportunity involving persons directly involved in the impending violent crime: three involved victims while nine involved both victims and the pending suspects. ${ }^{8}$ Therefore, responding officers could have potentially removed the 'motivated offender' and/or 'suitable target' 
from the situation at hand, or provided the necessary 'capable guardian' (Cohen and Felson, 1979) to deter the involved parties.

Unfortunately, the standard dispatch function of law enforcement does not make adequate use of the intervention opportunities discovered by CCTV, specifically since the differential response approach produces large queue times for most reported incidents. A potential solution may be for police to abandon differential response in CCTV-detected incidents by dispatching an officer immediately upon observation of an incident of concern. However, this policy would likely be a tough sell to citizens living outside of CCTV areas who are not likely to consider their emergencies as less important just because they were not captured on video. Immediate response in CCTV areas would also place additional burden on patrol units working in other areas of the city by tasking these officers with responding to a larger number of high-priority incidents.

A more viable solution may be to incorporate the video surveillance function into current proactive operations of the department, which echoes recommendations offered in prior research (for example, Gill and Spriggs, 2005; La Vigne and Lowry, 2011; La Vigne et al, 2011; Piza et al, 2012). In Baltimore, for example, surveillance operators routinely worked in conjunction with officers from the narcotics and bicycle patrol units, specifically by monitoring cameras in areas patrolled by these units and directly alerting officers when an incident was observed (La Vigne et al, 2011). The direct communication between the CCTV operators and street-level officers prevented the delay inherent in the differential-response policy of police dispatch. Given the lessons learned in Baltimore, similar proactive options seem to be available in the current study setting. For example, the Newark Police Department commonly deploys 'suppression units' for the purpose of identifying and addressing criminogenic conditions that may generate violence. These units have reduced, or no, responsibilities for responding to calls-for-service, but are tasked with enacting proactive enforcement actions within high-crime areas. These units could be integrated into the surveillance operation, so that they are notified when an operator detects an incident of concern. Police departments with existing CCTV infrastructure can make similar attempts to identify their pre-existing proactive operations that can best support, and benefit from, the integration of live CCTV monitoring.

It should be acknowledged, however, that in the current fiscal climate police departments (specifically American police departments) may not have the ability to conduct proactive operations as often as they are accustomed to. This is especially evident in the current study setting. Owing to massive police layoffs, the Newark Police Department was forced to discontinue one of their main proactive policing efforts, a saturation foot-patrol initiative named Operation Impact (Piza and O'Hara, 2012, p. 21). In the context of the current study, this represents one less program to potentially integrate with CCTV. Although it is unclear whether the situation in Newark is representative of the policing field as a whole, the recent economic decline has forced many police agencies to reconfigure their strategies in order to account for funding cutbacks (Wiseman, 2011). It is possible that such reconfigurations may result in the elimination, or downsizing, of certain proactive operations.

In recognition of such issues, police may be able to address potential pre-cursor events by soliciting the participation of other entities within CCTV target areas. In the event that the police themselves are not able to swiftly address a particular incident, the partnering entities can be notified and asked to intervene. A similar system of shared intervention responsibilities has been reported in prior research, specifically in the United Kingdom 
(Sarno et al, 1999; Gill et al, 2005; Norris and McCahill, 2006). For example, Norris and McCahill (2006, pp. 105-106) reported that interviews with CCTV system managers revealed a form of 'hybrid policing' in which CCTV operators report incidents to a wide range of partners. In a shop lifting incident, for example, the business manager, private security guards in the shopping center and police officers on patrol in the town center were all notified of the incident and suspect description. This allowed for a joint response in which the multiple parties support one another. Granted, many of the precursor incidents reported in the current study (for example, drug transactions and street fights) are not situations that non-police entities, such as business managers, can realistically address. However, given the nature of the CCTV sites, other law enforcement entities may have shared jurisdiction over the area. The Housing Authority, for example, operates a police force with jurisdiction within all Public Housing complexes in Newark. Furthermore, bars often employ armed security guards (who are oftentimes off-duty police officers) to provide guardianship within their premises. Since these entities have an interest in preventing serious crime at and around their facilities, police may be able to solicit their cooperation in addressing potential precursor incidents detected by CCTV operators.

The findings of this study also have implications relative to the active CCTV monitoring functions. Norris (2003) argued that CCTV operators 'rely on a set of normatively based, contextual rules to draw their attention to any behavior that disrupts the "normal." Put simply, behaviors are suspicious if they are unusual. But given that most people who are running are merely trying to catch a bus, those obscuring their face merely trying to mitigate the effects of a biting northerly wind, and those loitering, waiting for their friends, it is hardly surprising that such strategies are largely unproductive in identifying the deviant' (p. 265). Somewhat contrary to this position, interviews in the current study suggest that CCTV operators may be able to effectively identify instances of suspicion and criminal behavior. Each respondent displayed in-depth knowledge of the places and persons captured on video. When asked why they chose to observe certain cameras over others, each operator stated that they knew which areas were more prone to crime. A number of operators went beyond this general statement and provided specific examples. One operator stated the following when explaining why he observed a particular bar: 'This particular location has been very busy. We've had multiple calls for drug transactions, assaults in progress... a couple of weeks ago, there was a guy standing by that door [a side entrance] and [he] was showing off something in the back seat of his car to a few people. When the officers got there they saw a gun lying on the floor board of the car. Also, the gang detectives told us that this is a new Blood [gang] hangout and that this particular set is feuding with another set on [nearby street]. I make sure to watch this camera whenever I get the chance because there's a high likelihood of violence here'. Operators also displayed similar knowledge of particular people observed on camera, as displayed by the following quote: 'This guy is here all of the time. A few months ago [before the incident in question] he was shot in the leg right in the courtyard [at the same location]. That's why he's wearing that cast - he's still recovering from the shooting, obviously. It hasn't slowed him down, though. He's still out here with his crew every day selling drugs. It seems like they work for [name of a drug dealer]. Whenever he drives into the complex they walk right up to his car like they're checking in or something'. Egon Bittner (1970) once declared that police officers typically know 'the shops, stores, warehouses, restaurants, hotels, schools, playgrounds, and other public places in such a way that they can recognize at a glance whether what is going on within them is within the range 
or normalcy' (p. 90). Remarks by Newark's CCTV operators suggest that they developed a similar sense of CCTV target areas by monitoring these same places on a daily basis.

\section{Conclusion}

This study explored the prospect of utilizing CCTV in a preemptive manner to identify and address street-level incidents of concern preceding serious violent crime. Footage of nine violent crime incidents provided case studies suggesting that CCTV may hold promise as an early intervention mechanism. However, we note that it would be unwise to draw firm conclusions from such a small study. Despite this absence of generalizability, we believe that the study contributes positively to the field. Specifically, this study shows that CCTV does not function within a vacuum and provides food for thought regarding how the deployment of CCTV can occur in a manner that maximizes its effectiveness. It may not be enough for police to solely rely on the conspicuous presence of cameras to produce deterrence. Indeed, the mere existence of intervention opportunities in the current study suggests that offenders have little problem committing crime in sight of CCTV. ${ }^{9}$ Therefore, police should begin to think of how CCTV policies can incorporate proactive aspects of police response rather than emphasizing surveillance cameras as a stand-alone tactic. CCTV seems able to identify and direct police to risky situations that can generate crime. The early identification of such incidents by CCTV operators can afford police an opportunity to address the situation at hand and prevent escalation (Owen et al, 2006). Unfortunately, standard police procedures relating to crime reporting and officer dispatch seem ill-fit to address such situations. By altering the manner by which CCTV is utilized, police may be able to improve upon the crime prevention benefits of video surveillance systems.

The current study also has implications for the research community. Although research has predominantly focused on program outcomes (that is, achieved crime reductions) CCTV programs involve a range of activities, including the selection and maintenance of camera sites, monitoring of video footage by operators, response to incidents of concern by police officers, and the use of footage as evidence in prosecution. Since they all are likely related to program effect, to some extent, the field would benefit from increased analysis of such procedural aspects of CCTV. From a theoretical perspective, such research can help solve what McGloin and Thomas (2013) refer to as the 'black box problem' where research focuses on program effect absent an understanding of the contextual mechanisms and theoretical underpinnings of the intervention. Increased research on CCTV's contextual mechanisms may help to develop what Gill and Spriggs (2005) refer to as 'transferable lessons that enable good practice in one area to be repeated in another' (p. 6). Given the substantial worldwide investments in CCTV, such an approach seems prudent.

\section{Acknowledgements}

We express our gratitude to Sergeant Marvin Carpenter and the surveillance operators of the Newark Police Department for their generous support. This study would not have been possible without their high level of cooperation. 


\section{Notes}

1 See Phillips (1999, p. 126) for a list and brief explanation of these mechanisms.

2 As defined by the Federal Bureau of Investigation's Uniformed Crime Report, Part 1 violent crime is comprised of four offenses: murder and non-negligent manslaughter, forcible rape, robbery, and aggravated assault (see: http:// www.fbi.gov/about-us/cjis/ucr/crime-in-the-u.s/2012/crime-in-the-u.s.-2012/violent-crime/violent-crime).

3 See Piza et al (2012, pp. 9-11) for a more detailed description of the operationalization of these variables.

4 A total of 12450 incidents occurred in CCTV areas during the study period. However, 1651 were excluded from the analysis due to the call being canceled before an officer was dispatched or arrived on scene. Cancelation primarily occurs for two reasons. One, the reporting party informs the police that a response is no longer necessary. Two, CCTV operators may notify the dispatcher that no visual evidence exists to support a complainant's claim that a crime occurred. For example, a caller may report a large fight at a certain street corner only for a CCTV operator to report that no such incident is taking place.

5 In the lone incident lacking an intervention opportunity, the camera operator was monitoring the outside of a bar following a 9-1-1 call about a dispute occurring within the establishment. A patron was ejected from the establishment and later returned with a baseball bat and attacked the bouncers. The lack of an observed intervention opportunity is likely attributable to the fact that the events leading to the assault occurred indoors and not in the public space viewable by the operators.

6 The MTI variable was converted from hours/minutes/seconds format to a continuous numeric value for the purpose of maintaining clarity. In this sense, the time interval of $1 \mathrm{~min}$ and 30 seconds is represented as ' 1.5 minutes' since 30 seconds is one-half $(0.5)$ of a full minute.

7 Although this finding may surprise some, prior research has produced similar findings. Gill et al (2005), for example, found that operators across 13 control rooms only informed police of 24 per cent of the offenses they observed.

8 Incident $\mathrm{F}$ did not have an identified intervention opportunity while a couple involved in a domestic dispute on a busy street corner in incident ' $G$ ' were not involved in a robbery that later occurred at the same location.

9 Although we are not able to definitively state that the offenders knew cameras were present, site visits to the crime scenes confirm that the incidents occurred within feet of the cameras. Therefore, we find it reasonable to assume that persons on the scene were knowledgeable of the cameras.

\section{References}

American Civil Liberties Union (ACLU). (2002) What's wrong with public video surveillance?, http://www.aclu .org/technology-and-liberty/whats-wrong-public-video-surveillance, accessed 30 August 2013.

Apel, R. (2013) Sanctions, perceptions, and crime: Implications for criminal deterrence. Journal of Quantitative Criminology 29(1): 67-101.

Bittner, E. (1970) The Functions of the Police in a Modern Society. New York: Aronson.

Boba, R. (2009) Crime Analysis with Crime Mapping, 2nd edn. Thousand Oaks, CA: Sage Publications.

Bulos, M. and Sarno, C. (1996) Codes of Practice and Public Closed Circuit Television Systems. London: Local Government Information Unit.

Cameron, A., Kolodinski, E., May, H. and Williams, N. (2008) Measuring the effects of video surveillance on crime in Los Angeles, Report prepared for the California Research Bureau. USC School of Policy, Planning, and Development.

Caplan, J., Kennedy, L. and Petrossian, G. (2011) Police-monitored cameras in Newark, NJ: A quasi-experimental test of crime deterrence. Journal of Experimental Criminology 7(3): 255-274.

Clarke, R. (ed.) (1997) Introduction. In: Situational Crime Prevention, Successful Case Studies, 2nd edn. Monsey, NY: Criminal Justice Press, pp. 1-43.

Cohen, L. and Felson, M. (1979) Social change and crime rate trends: A routine activity approach. American Sociological Review 44(4): 588-605.

Cornish, D. and Clarke, R. (1987) Understanding crime displacement: An application of rational choice theory. Criminology 25(4): 933-947.

Cornish, D. and Clarke, R. (1986) The Reasoning Criminal: Rational Choice Perspectives on Offending. New York: Springer-Verlag. 
Ditton, J. and Short, E. (1999) Yes it works. No it doesn't: Comparing the effects of open-street CCTV is two adjacent Scottish town centres. In: N. Tilley and K. Painter (eds.) Surveillance of Public Space: CCTV, Street Lighting and Crime Prevention. Crime Prevention Studies, Vol. 10. Monsey, NY: Criminal Justice Press, pp. 201-224.

Dumbra v. United States. (1925) 268 US 435-Supreme Court.

Durlauf, S. and Nagin, D. (2011) Imprisonment and crime: Can both be reduced? Criminology and Public Policy 10(1): 13-54.

Farrington, D., Gill, M., Waples, S. and Argomaniz, J. (2007) The effects of closed-circuit television on crime: Meta-analysis of an English national quasi-experimental multi-site evaluation. Journal of Experimental Criminology 3(1): 21-28.

Feagin, J., Orum, A. and Sjoberg, G. (eds.) (1991) A Case for the Case Study. Chapel Hill, NC: University of North Carolina Press.

Gill, M. and Hemming, M. (2004) Evaluation of CCTV in the London Borough of Lewisham. Leicester, UK: Perpetuity Research \& Consultancy International (PRCI).

Gill, M. and Spriggs, A. (2005) Assessing the Impact of CCTV, (Home Office Research Study No. 292). London: Home Office.

Gill, M., Spriggs, A., Allen, J., Hemming, M., Jessiman, P. and Kara, D. (2005) Control Room Operation: Findings form Control Room Observations. London: Home Office.

Hammersley, M. (ed.) (1992) So, what are case studies? In: What's Wrong with Ethnography. London: Routledge, pp. 183-200.

Jacobs, B., Topalli, V. and Wright, R. (2000) Managing retaliation: Drug robbery and informal sanction threats. Criminology 38(1): 171-198.

Kennedy, L. and Van Brunschot, E. (2009) The Risk in Crime. Lanham, MD: Roman \& Littlefield Publishers.

Keval, H. and Sasse, M. (2010) 'Not the usual suspects': A study of factors reducing the effectiveness of CCTV. Security Journal 23(2): 134-154.

King, J., Mulligan, D. and Raphael., S. (2008) The San Francisco Community Safety Camera Program, Research in the Interest of Society. Berkeley, CA: Center for Information Technology, University of California.

La Vigne, N. and Lowry, S. (2011) Evaluation of Camera use to Prevent crime in Commuter Parking lots: A Randomized Controlled Trial. Washington DC: Urban Institute, Justice Policy Center.

La Vigne, N., Lowry, S., Markman, J. and Dwyer, Al. (2011) Evaluating the use of Public Surveillance Cameras for Crime Control and Prevention. Washington DC: US Department of Justice, Office of Community Oriented Policing Services. Urban Institute, Justice Policy Center.

Law Enforcement Information Technology Standards Council [LEITSC]. (2008) Standard Functional Specifications for Law Enforcement Computer Aided Dispatch (CAD) Systems. Washington DC: US Department of Justice, Office of Justice Programs, Bureau of Justice Assistance, and the National Institute of Justice.

Leman-Langlois, S. (2002) The myopic panopticon: The social consequences of policing through the lens. Policing and Society 13(1): 43-58.

Lomell, H. (2004) Targeting the unwanted: Video surveillance and categorical exclusion in Oslo, Norway. Surveillance\& Society 2(2/3): 346-360.

Loveday, K. and Gill, M. (2004) The impact of monitored CCTV in a retail environment: What CCTV operators do and why. Crime Prevention and Community Safety: An International Journal 6(3): 43-55.

Lum, C. and Kennedy, L. (2012) In support of evidence-based approaches: A rebuttal to Gloria Laycock. Policing: A Journal of Policy and Practice 6(4): 317-323.

Lyon, D. (ed.) (2003) Introduction. In: Surveillance as Social Sorting: Privacy, Risk and Digital Discrimination. London and New York: Routledge, pp. 1-10.

Mazerolle, L., Hurley, D. and Chamlin, M. (2002) Social behavior in public space: An analysis of behavioral adaptations to CCTV. Security Journal 15(3): 59-75.

McGloin, J. and Thomas, K. (2013) Experimental tests of criminological theory. In: B. Welsh, A. Braga and G. Bruinsma (eds.) Experimental Criminology: Prospects for Advancing Science and Public Policy. New York: Cambridge University Press, pp. 15-42.

Norris, C. (2003) From personal to digital: CCTV, the panopticon, and the technological mediation of suspicion and social control. In: D. Lyon (ed.) Surveillance as Social Sorting: Privacy, Risk and Digital Discrimination. London and New York: Routledge, pp. 249-281.

Norris, C. and Armstrong, G. (1999a) CCTV and the social structuring of surveillance. In: N. Tilley and K. Painter (eds.) Surveillance of Public Space: CCTV, Street Lighting and Crime Prevention, Crime Prevention Studies. Vol. 10. Monsey, NY: Criminal Justice Press, pp. 157-178. 
Norris, C. and Armstrong, G. (1999b) The Maximum Surveillance Society: The Rise of CCTV. Oxford and New York: Berg.

Norris, C. and McCahill, M. (2006) CCTV: Beyond penal modernism? British Journal of Criminology 46(1): 97-118.

Owen, K., Keats, G. and Gill, M. (2006) A Short Evaluation of the (Economic) Benefits of the Milton Keynes CCTV System in Managing Police Resources. Tunbridge Wells, UK: Perpetuity Research \& Consultancy International (PRCI) Ltd.

Painter, K. and Tilley, N. (eds.) (1999) Seeing and being seen to prevent crime. In: Surveillance of Public Space: CCTV, Street Lighting and Crime Prevention. Crime Prevention Studies, Vol. 10. Monsey, NY: Criminal Justice Press, pp. 1-14.

Pawson, R. and Tilley, N. (1994) What works in evaluation research? British Journal of Criminology 34(3): 291-306.

Phillips, C. (1999) A review of CCTV evaluations: Crime reduction effects and attitudes towards its use. In: N. Tilley and K. Painter (eds.) Surveillance of Public Space: CCTV, Street Lighting and Crime Prevention, Crime Prevention Studies. Vol. 10. Monsey, NY: Criminal Justice Press, pp. 123-155.

Piza, E. and O'Hara, B. (2012) Saturation foot-patrol in a high-violence area: A quasi-experimental evaluation. Justice Quarterly. Published online 12 March, doi:10.1080/07418825.2012.668923.

Piza, E., Caplan, J. and Kennedy, L. (2012) Is the punishment more certain? An analysis of CCTV detections and enforcement. Justice Quarterly. Published online 11 September, doi:10.1080/07418825.2012.723034.

Piza, E., Caplan, J. and Kennedy, L. (2013) Analyzing the influence of micro-level factors on CCTV camera effect. Journal of Quantitative Criminology. Published online 31 May, doi:10.1007/s10940-013-9202-5.

Platt, J. (2007) Case study. In: W. Outhwiate and S. Turner (eds.) The Sage Handbook of Social Science Methodology. London: SAGE Publications, pp. 100-118.

Ratcliffe, J. (2006) Video Surveillance of Public Places. Problem-Oriented Guides for Police. Response Guide Series. Guide No. 4, US Department of Justice Office of Community Oriented Policing Services, Center for Problem-Oriented Policing.

Ratcliffe, J. and Rengert, G. (2008) Near-repeat patterns in Philadelphia shootings. Security Journal 21(1-2): 58-76.

Ratcliffe, J., Taniguchi, T. and Taylor, R. (2009) The crime reduction effects of public CCTV cameras: A multimethod spatial approach. Justice Quarterly 26(4): 746-770.

Reid, A. and Andresen, M. (2014) An evaluation of CCTV in a car park using police and insurance data. Security Journal 27(1): 57-79.

Sacco, V. and Kennedy, L. (2002) The Criminal Event: Perspectives in Space and Time. Belmont, CA: Wadsworth.

Sarno, C., Hough, M. and Bulos, M. (1999) Developing a Picture of CCTV in Southwark Towne Centres: Final Report. London: Criminal Policy Research Unit, South Bank University.

Smith, G. (2004) Behind the scenes: Examining constructions of deviance and informal practices among CCTV control room operators in the UK. Surveillance \& Society 2(2/3): 376-395.

Sparrow, M. (2011) Governing science. New Perspectives in Policing Series, Harvard Executive Session on Policing and Public Safety. Cambridge, MA: Harvard Kennedy School of Government, Washington DC: National Institute of Justice.

Terry v. Ohio. (1968) 392 US 1, 88 S.Ct. 1868, 20 L.Ed.2d 889.

Tilley, N. (1993) Understanding car Parks, Crime and CCTV, Crime Prevention Unit Series Paper 42. London, UK: Home Office.

Usher, N. (2003) Video surveillance comes to big easy. San Diego Union-Tribune 24 August.

Waples, S. and Gill, M. (2006) The effectiveness of redeployable CCTV. Crime Prevention and Community Safety: An International Journal 8(1): 1-16.

Welsh, B. and Farrington, D. (2009) Public area CCTV and crime prevention: An updated systematic review and meta-analysis. Justice Quarterly 26(4): 716-745.

Wiseman, J. (2011) Strategic Cutback Management: Law Enforcement Leadership for Lean Times. Washington DC: US Department of Justice, Office of Justice Programs, National Institute of Justice. 